\title{
Short communication: Antimethanogenic effects of 3-nitrooxypropanol depend on supplementation dose, dietary fiber content, and cattle type
}

\author{
J. Dijkstra, ${ }^{*}$ A. Bannink, $†$ J. France, $\ddagger$ E. Kebreab, $\S^{1}$ and S. van Gastelen*† \\ *Animal Nutrition Group, Wageningen University \& Research, $6700 \mathrm{AH}$, Wageningen, the Netherlands \\ †Animal Nutrition, Wageningen Livestock Research, Wageningen University and Research, PO Box 338, $6700 \mathrm{AH}$, Wageningen, the Netherlands \\ $\ddagger$ Centre for Nutrition Modelling, Department of Animal Biosciences, University of Guelph, Guelph, ON N1G 2W1, Canada \\ §Department of Animal Science, University of California, Davis 95616
}

\section{ABSTRACT}

3-Nitrooxypropanol (NOP) is a promising methane $\left(\mathrm{CH}_{4}\right)$ inhibitor. Recent studies have shown major reductions in $\mathrm{CH}_{4}$ emissions from beef and dairy cattle when using NOP but with large variation in response. The objective of this study was to quantitatively evaluate the factors that explain heterogeneity in response to NOP using meta-analytical approaches. Data from 11 experiments and 38 treatment means were used. Factors considered were cattle type (dairy or beef), measurement technique (GreenFeed technique, C-Lock Inc., Rapid City, SD; sulfur hexafluoride tracer technique; and respiration chamber technique), dry matter (DM) intake, body weight, NOP dose, roughage proportion, dietary crude protein content, and dietary neutral detergent fiber (NDF) content. The mean difference (MD) in $\mathrm{CH}_{4}$ production $(\mathrm{g} / \mathrm{d})$ and $\mathrm{CH}_{4}$ yield $(\mathrm{g} / \mathrm{kg}$ of DM intake) was calculated by subtracting the mean of $\mathrm{CH}_{4}$ emission for the control group from that of the NOP-supplemented group. Forest plots of standardized MD indicated variable effect sizes of NOP across studies. Compared with beef cattle, dairy cattle had a much larger feed intake $(22.3 \pm 4.13$ vs. $7.3 \pm 0.97 \mathrm{~kg}$ of $\mathrm{DM} / \mathrm{d}$; mean \pm standard deviation) and $\mathrm{CH}_{4}$ production $(351 \pm 94.1$ vs. $124 \pm 44.8 \mathrm{~g} / \mathrm{d})$. Therefore, in further analyses across dairy and beef cattle studies, MD was expressed as a proportion (\%) of observed control mean. The final mixed-effect model for relative MD in $\mathrm{CH}_{4}$ production included cattle type, NOP dose, and NDF content. When adjusted for NOP dose and NDF content, the $\mathrm{CH}_{4}$-mitigating effect of NOP was less in beef cattle $(-22.2 \pm 3.33 \%)$ than in dairy cattle $(-39.0$ $\pm 5.40 \%)$. An increase of $10 \mathrm{mg} / \mathrm{kg}$ of DM in NOP dose from its mean (123 mg/kg of DM) enhanced the NOP effect on $\mathrm{CH}_{4}$ production decline by $2.56 \pm 0.550 \%$.

Received January 16, 2018.

Accepted June 8, 2018.

${ }^{1}$ Corresponding author: ekebreab@ucdavis.edu
However, a greater dietary NDF content impaired the NOP effect on $\mathrm{CH}_{4}$ production by $1.64 \pm 0.330 \%$ per 10 $\mathrm{g} / \mathrm{kg}$ DM increase in NDF content from its mean (331 $\mathrm{g}$ of $\mathrm{NDF} / \mathrm{kg}$ of $\mathrm{DM}$ ). The factors included in the final mixed-effect model for $\mathrm{CH}_{4}$ yield were $-17.1 \pm 4.23 \%$ (beef cattle) and $-38.8 \pm 5.49 \%$ (dairy cattle), -2.48 $\pm 0.734 \%$ per $10 \mathrm{mg} / \mathrm{kg}$ DM increase in NOP dose from its mean, and $1.52 \pm 0.406 \%$ per $10 \mathrm{~g} / \mathrm{kg}$ DM increase in NDF content from its mean. In conclusion, the present meta-analysis indicates that a greater NOP dose enhances the NOP effect on $\mathrm{CH}_{4}$ emission, whereas an increased dietary fiber content decreases its effect. 3-Nitrooxypropanol has stronger antimethanogenic effects in dairy cattle than in beef cattle.

Key words: 3-nitrooxypropanol, cattle, methane

\section{Short Communication}

Enteric methane $\left(\mathrm{CH}_{4}\right)$ production is among the main targets of greenhouse gas mitigation practices for the dairy and beef production sector. Several $\mathrm{CH}_{4}-$ mitigation strategies have been proposed, including improving genetic potential, reproductive efficiency, and health of animals; increasing animal productivity; improving forage quality; and using feed additives (Hristov et al., 2013a,b). Recently, a compound called 3-nitrooxypropanol (NOP) has been reported to substantially decrease $\mathrm{CH}_{4}$ emissions from ruminants (Duin et al., 2016). The molecular shape of NOP is similar to that of methyl-coenzyme M, and NOP specifically targets methyl-coenzyme $\mathrm{M}$ reductase (MCR), which catalyzes the last step in the $\mathrm{CH}_{4}$-forming pathway of rumen archaea (Duin et al., 2016). Several studies have investigated the effects of NOP on $\mathrm{CH}_{4}$ emission in cattle, but the results have not been fully consistent. Large variation in response to addition of NOP was reported; namely, between a decrease of $84.3 \%$ (Vyas et al., 2016) and an increase of $7.1 \%$ (Vyas et al., 2018) in $\mathrm{CH}_{4}$ production compared with the control diet. In a recent meta-analysis, Jayanegara et al. (2018) 
showed that increasing levels of NOP addition in diets of ruminants decreased enteric $\mathrm{CH}_{4}$ emissions. In the present meta-analysis, we hypothesize that (in addition to NOP dose), DMI, nutrient composition of the diet, $\mathrm{BW}$, and type of animal might explain the variability in NOP effect. The objective of this study was to quantitatively evaluate the factors that explain heterogeneity in response to NOP using meta-analytical approaches.

Literature searches of the Web of Science (Thomson Reuters Science, New York, NY), CAB Direct (CAB International, Wallingford, UK), and Scopus (Elsevier, Amsterdam, the Netherlands) online databases were conducted using keywords "NOP" (including all variants, such as "nitrooxypropanol") + "cattle" + "methane" (or " $\mathrm{CH}_{4}$ "). The search resulted in 12 articles related to effect of NOP on methane emissions. For inclusion in the database, the studies were required to include a control treatment group that did not receive NOP, to be conducted in vivo using cattle, and to include measured $\mathrm{CH}_{4}$ production. Two articles were rejected because they reported in vitro experiments only. Another study (a short communication) was rejected because it repeated data from another paper included in our analysis. Data from 9 articles (11 experiments) met the selection criteria, and 38 treatment means were used for dairy cattle (Haisan et al., 2014, 2017; Reynolds et al., 2014; Hristov et al., 2015; Lopes et al., 2016) and beef cattle (Romero-Perez et al., 2014, 2015; Vyas et al., 2016, 2018). 3-Nitrooxypropanol was delivered twice daily directly into the rumen (Reynolds et al., 2014), top-dressed on a TMR that was offered once daily (Romero-Perez et al., 2014; NOP consumed by animals within 10 min of presentation), or was mixed in a TMR that was offered once daily (all others; continuous NOP dose). Methane emissions were estimated using the respiration chamber technique ( 7 studies; 1 involving dairy cattle and 6 involving beef cattle), the sulfur hexafluoride $\left(\mathrm{SF}_{6}\right)$ tracer technique (2 studies, both involving dairy cattle), or the GreenFeed technique (2 studies, both involving dairy cattle; C-Lock Inc., Rapid City, SD). Usually, $\mathrm{CH}_{4}$ production was reported in grams per day and $\mathrm{CH}_{4}$ yield in grams per kilogram of DMI consumed. If reported in liters rather than grams, the values were converted assuming a molar weight of $16.0 \mathrm{~g}$ and volume of $22.4 \mathrm{~L}$, respectively. A summary of the database is presented in Table 1.

Effect size estimates and corresponding sampling variances were obtained using the "metaphor" (version 2.0-0) and "robumeta" (version 2.0) packages in R (version 3.1.1, R Foundation for Statistical Computing, Vienna, Austria). The mean difference (MD) of $\mathrm{CH}_{4}$ production or $\mathrm{CH}_{4}$ yield was calculated as NOP treatment mean minus control treatment mean. Individual studies were weighted by their corresponding sample variation

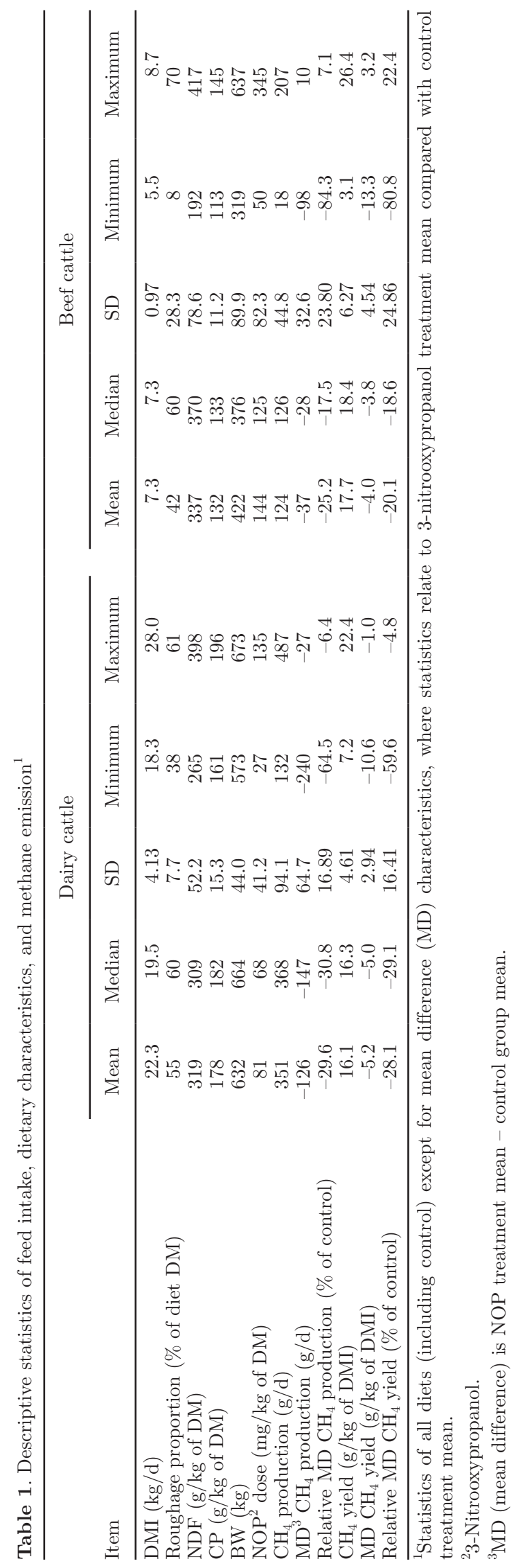


according to Viechtbauer (2010), and standardized mean differences $(\mathbf{S M D} ; \mathrm{SMD}=\mathrm{MD} /$ pooled standard deviation of the 2 groups) were used to construct forest plots of $\mathrm{CH}_{4}$ production and $\mathrm{CH}_{4}$ yield. The magnitude of DMI and $\mathrm{CH}_{4}$ production of the control treatment varied greatly from study to study, and DMI and $\mathrm{CH}_{4}$ production were greater in dairy cattle than in beef cattle. Hence, relative MD [MD expressed as a fraction (in \%) of observed control mean] was the effect size in further analyses. Relative MD was checked for normality using the "qqnorm" function in R. The studies in this meta-analysis contain multiple treatment groups sharing a common control group; hence, the effect size estimates are not statistically independent. Therefore, a robust variance estimation $(\mathbf{R V E})$ method (TannerSmith et al., 2016) was used to analyze statistically dependent effect sizes in this meta-analysis. Randomeffects and mixed-effects models were fitted using the "robu" function in the "robumeta" package (Fisher and Tipton, 2014). The random-effect models were fitted to estimate between-study variance $\left(\tau^{2}\right)$ and heterogeneity $\left(\boldsymbol{I}^{2}\right)$ statistics. The RVE random-effect model was given by

$$
y_{i j}=\zeta+u_{j}+e_{i j}
$$

where for $i=1, \ldots, k_{j}, j=1, \ldots, m, y_{i j}$ is the $i$ th effect size in study $j, \zeta$ is the average population effect, $u_{j}$ is the study-level random effect such that $\operatorname{Var}\left(u_{j}\right)=\tau^{2}$ is the between-study variance component; and $e_{i j}$ is the residual for the $i$ th effect size in the $j$ th study, such that $\operatorname{Var}\left(e_{i j}\right)=s i^{2}$ is the error variance component. The proportion of total variation in study estimates that is due to heterogeneity $\left(I^{2}\right)$ is calculated as $\tau^{2}$ divided by the sum of $s_{i}^{2}$ (sample variance) and $\tau^{2}$. An $I^{2}$ value $>50 \%$ indicates considerable heterogeneity (Rabiee et al., 2010). Heterogeneity measures the degree to which data from multiple studies observing the same effect overlap with one another. To reduce heterogeneity, the RVE random-effect models can be extended to include variables having the potential to explain heterogeneity. The RVE mixed-effect meta-regression model was given by

$$
y_{i j}=\zeta_{0}+u_{j}+\mathbf{X}_{i j} \boldsymbol{\beta}+e_{i j},
$$

where $\zeta_{0}$ is the overall effect size, $\mathbf{X}_{i j}$ is a vector of different continuous explanatory variables or binary variables to indicate categories, $\boldsymbol{\beta}$ is a vector of the effect of the explanatory variables on the effect size, and $u_{j}$ and $e_{i j}$ are as defined previously. For nested models, Hedges et al. (2010) developed a method for estimating inverse variance weights, which was used in this study:

$$
w_{i j}=1 /\left[k_{j}\left(v_{\cdot j}+\tau^{2}\right)\right],
$$

where $w_{i j}$ is the $i$ th inverse variance weight in study $j$, $v_{\cdot j}$ is the mean of the within-study sampling variances $\left(v_{i j}\right)$ for the $k_{j}$ effect sizes in study $j, \tau^{2}$ is the estimate of the between-study variance component, and $k_{j}$ is the number of effect sizes within each study $j$. The RVE mixed-effect meta-regression models were constructed by including one or more explanatory variables with the "robu" function in a stepwise manner. First, models including individual explanatory variables were fitted. Full mixed-effect models were obtained by stepwise inclusion of individual explanatory variables, retaining the variables with $P<0.10$. Quadratic effects of continuous variables were evaluated but not included in the final model $(P>0.10)$.

We used dairy cattle and beef cattle as category variables, in which case $\boldsymbol{\beta}$ represents the difference in true effect size between dairy and beef cattle. Measurement technique was also used as a categorical variable. The proportion of roughage in the diet, DMI, BW, and the dietary contents of NOP, NDF, and CP were potential continuous explanatory variables, and then $\boldsymbol{\beta}$ represents the change in the true effect size for each unit increase in the continuous explanatory variable. Other potential explanatory variables, such as dietary starch content, OM digestibility, and VFA profile were considered. However, these variables could not be included in the analysis because only a few studies reported these variables. Correlation between explanatory variables was investigated using the "cor" function in R. Correlated variables, such as NDF and roughage proportion $\left(\mathrm{R}^{2}=0.75\right), \mathrm{CP}$ and DMI $\left(\mathrm{R}^{2}=0.71\right)$, and $\mathrm{BW}$ and DMI $\left(\mathrm{R}^{2}=0.79\right)$, were not used in the same model (i.e., criteria correlation coefficient $>0.50$ ). Values of each continuous explanatory variable were centered on their means before analysis. Such a rearrangement allows interpretation of the regression effects in terms of changes in NOP effect size for a unit change in an explanatory variable from its mean.

Meta-analyses aim to synthesize evidence from many possible sources, by comparing and combining findings from several studies using statistical methods (Madden and Paul, 2011). The meta-analysis in the present paper summarizes the effects of NOP in both dairy and beef cattle related to $\mathrm{CH}_{4}$ production $(\mathrm{g} / \mathrm{d})$ and $\mathrm{CH}_{4}$ yield $(\mathrm{g} / \mathrm{kg}$ of DMI). Standardized MD are presented in Figure $1\left(\mathrm{CH}_{4}\right.$ production) and Figure $2\left(\mathrm{CH}_{4}\right.$ yield $)$ using forest plots. These plots graphically show the relative strength of averaged treatment effects in the studies included. The forest plots indicate that NOP had mostly consistent antimethanogenic effects, but effect sizes were variable across studies. On average, the 
NOP dose (in $\mathrm{mg} / \mathrm{kg}$ of $\mathrm{DM}$ ) used in dairy cattle was smaller, and the relative $\mathrm{MD}$ in $\mathrm{CH}_{4}$ production and $\mathrm{CH}_{4}$ yield higher, than in beef cattle (Table 1). Using RVE random-effects models, an average dose of $123 \mathrm{mg}$ of NOP $/ \mathrm{kg}$ of DM in dairy and beef cattle reduced $\mathrm{CH}_{4}$ production $(P<0.001)$ by $32.5 \pm 5.74 \%$ and $\mathrm{CH}_{4}$ yield $(P<0.001)$ by $29.3 \pm 5.63 \%$ (Table 2$)$. Such reduction levels are quantitatively comparable with nitrate, a well-known $\mathrm{CH}_{4}$ inhibitor, if fed at levels exceeding $2 \%$ of diet DM (Olijhoek et al., 2016), but they are much higher than for other $\mathrm{CH}_{4}$ inhibitors, including essential oils (Benchaar and Greathead, 2011) and monensin (Appuhamy et al., 2013). The effects of NOP were associated with large heterogeneity across dairy cows and beef steers. More than $99 \%$ of the total variability of the NOP effects in $\mathrm{CH}_{4}$ production and $\mathrm{CH}_{4}$ yield was due to heterogeneity $\left(I^{2}>99 \%\right)$, indicating genuine differences underlying the results of the studies used in the present analysis.

To understand possible causes of the high heterogeneity, individual explanatory variables were evaluated in RVE mixed-effects meta-regression models. For relative $\mathrm{MD}$ in $\mathrm{CH}_{4}$ production, the categorical variables cattle type (dairy or beef; $P=0.973$ ) and measurement tech- nique $(P=0.393)$, and the continuous variables DMI $(P=0.984), \mathrm{BW}(P=0.519)$, dietary $\mathrm{CP}$ content $(P$ $=0.909)$, dietary roughage proportion $(P=0.381)$, and dietary NDF content $(P=0.131)$ were not significant. For relative MD in $\mathrm{CH}_{4}$ yield, the categorical variables cattle type (dairy or beef; $P=0.715$ ) and measurement technique $(P=0.365)$, and the continuous variables DMI $(P=0.672)$, BW $(P=0.267)$, dietary CP content $(P=0.963)$, dietary roughage proportion $(P=0.640)$, and dietary NDF content $(P=0.165)$ were not significant. However, the effectiveness of NOP at mitigating $\mathrm{CH}_{4}$ emissions was positively associated with dietary NOP content. A $10 \mathrm{mg} / \mathrm{kg}$ of DM increase in NOP dose from its mean $(123 \mathrm{mg} / \mathrm{kg}$ of DM) enhanced $(P=0.016)$ the NOP effect on $\mathrm{CH}_{4}$ production decline by $1.76 \pm$ $0.441 \%$ and enhanced $(P=0.043)$ that on $\mathrm{CH}_{4}$ yield decline by $1.58 \pm 0.544 \%$ (Table 2 ). The nickel enzyme MCR that catalyzes $\mathrm{CH}_{4}$ formation in methanogenic archaea is inactivated by NOP, but the actual levels of NOP required to inhibit growth and $\mathrm{CH}_{4}$ production of individual methanogens vary widely (Duin et al., 2016). Increasing the NOP dose may target a greater number of methanogenic archaeal species, resulting in a more pronounced decline in $\mathrm{CH}_{4}$ production. Although

Authors and Year Type 3NOP dose $(\mathrm{mg} / \mathrm{kg})$

Mean Difference $[95 \% \mathrm{Cl}]$

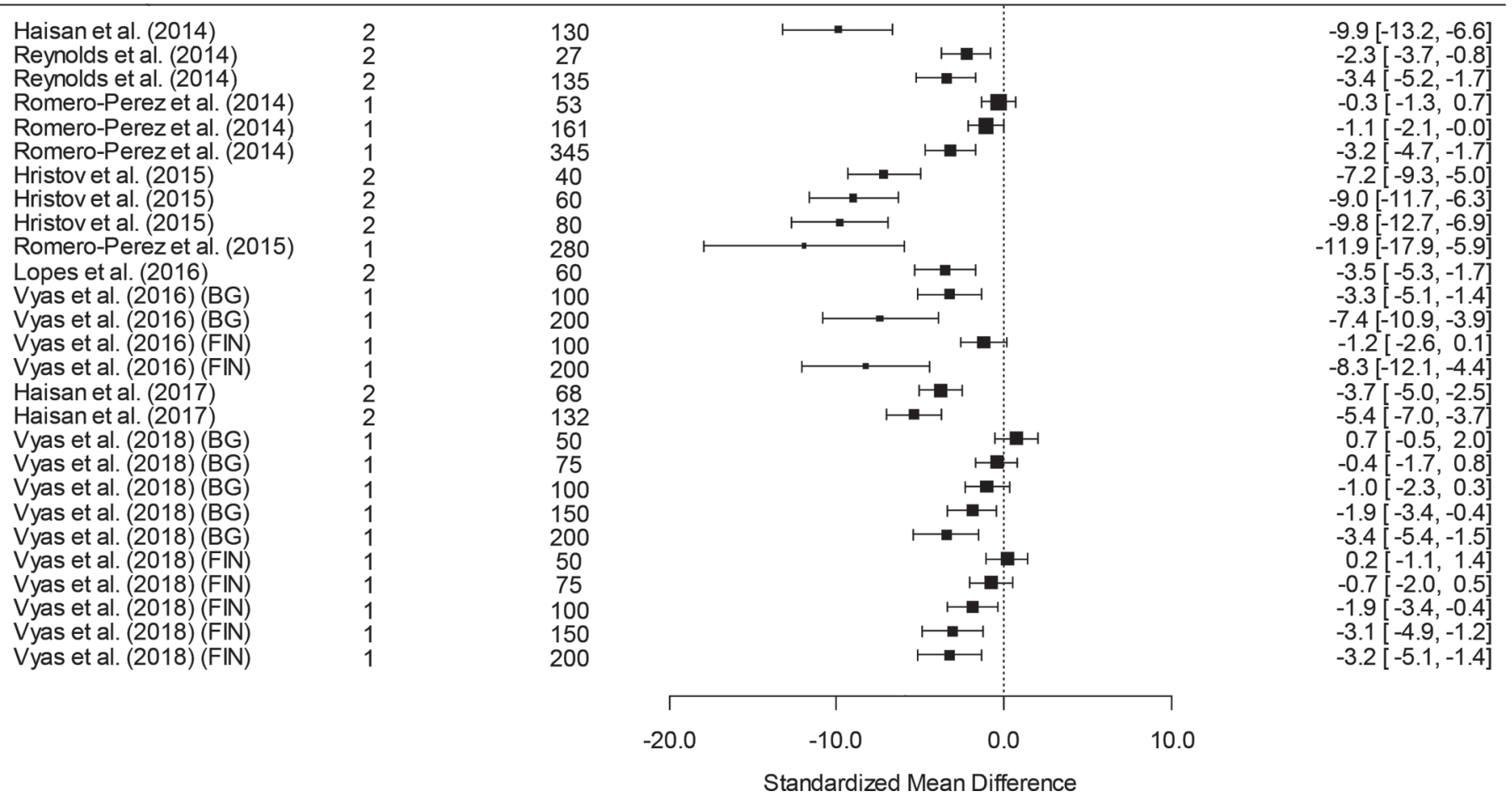

Figure 1. Forest plot showing 3-nitrooxypropanol (3NOP) dose $(\mathrm{mg} / \mathrm{kg}$ of DM) and standardized mean difference (mean difference is calculated as NOP treatment mean - control treatment mean) in $\mathrm{CH}_{4}$ production $(\mathrm{g} / \mathrm{d})$ for beef (type $\left.=1\right)$ and dairy $($ type $=2)$ cattle studies. $\mathrm{BG}$ = backgrounding diet; FIN = finishing diet. The black squares represent the power of the study (i.e., greater sample sizes and smaller confidence intervals are indicated by a larger box). 
Table 2. Estimates of overall 3-nitrooxypropanol (NOP) effect size and of explanatory variables ${ }^{1}$ from random- and mixed-effect models for relative mean difference ${ }^{2}(\mathrm{MD})$ in $\mathrm{CH}_{4}$ production $(\mathrm{g} / \mathrm{d})$ and yield $(\mathrm{g} / \mathrm{kg}$ of DMI)

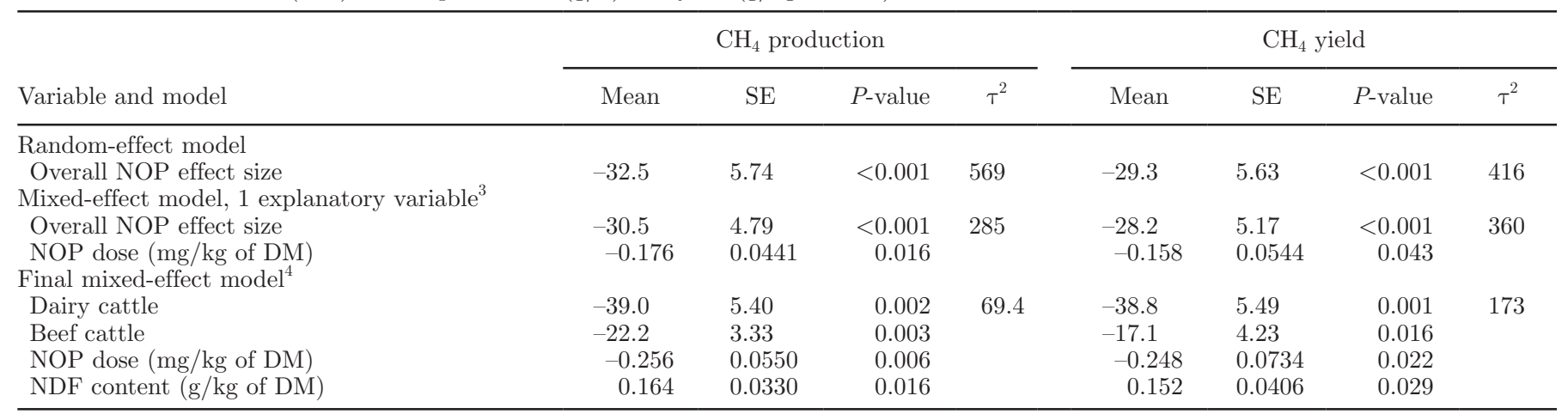

${ }^{1}$ Explanatory variables centered on the mean, except variable cattle type. Mean values: NOP dose $=123 \mathrm{mg} / \mathrm{kg}$ of DM; dietary NDF content $=$ $331 \mathrm{~g} / \mathrm{kg}$ of DM; dietary CP content $=147 \mathrm{~g} / \mathrm{kg}$ of DM; roughage proportion $=47 \%$ of diet DM; DMI $=22.3 \mathrm{~kg} / \mathrm{d}, \mathrm{BW}=527 \mathrm{~kg}$.

${ }^{2} \mathrm{MD}$ is NOP treatment mean $\mathrm{CH}_{4}$ production or yield - control group mean $\mathrm{CH}_{4}$ production or yield; relative $\mathrm{MD}$ is $\mathrm{MD}$ as a fraction (\%) of control; control group average $\mathrm{CH}_{4}$ production is 429 and $154 \mathrm{~g} / \mathrm{d}$ for dairy cattle and beef cattle, respectively. Control group average $\mathrm{CH}_{4}$ yield is 19.6 and $21.3 \mathrm{~g} / \mathrm{kg}$ of DM for dairy cattle and beef cattle, respectively.

${ }^{3}$ In mixed-effect models with 1 explanatory variable, the variables cattle type $(P=0.973)$, measurement technique $(P=0.393)$, DMI $(P=$ $0.984)$, BW $(P=0.519)$, dietary $\mathrm{CP}$ content $(P=0.909)$, roughage proportion $(P=0.381)$, and NDF content $(P=0.131)$ were not significant for $\mathrm{CH}_{4}$ production. The variables cattle type $(P=0.715)$, measurement technique $(P=0.365)$, DMI $(P=0.672), \mathrm{BW}(P=0.267)$, dietary $\mathrm{CP}$ content $(P=0.963)$, roughage proportion $(P=0.640)$, and NDF content $(P=0.165)$ were not significant for $\mathrm{CH}_{4}$ yield.

${ }^{4}$ Species effect $P$-value $<0.001$ for both $\mathrm{CH}_{4}$ production and yield.

Authors and Year

Haisan et al. (2014)
Reynolds et al. (2014)
Reynolds et al. (2014)
Romero-Perez et al. (2014)
Romero-Perez et al. (2014)
Romero-Perez et al. (2014)
Hristov et al. (2015)
Hristov et al. (2015)
Hristov et al. (2015)
Romero-Perezet al. (2015)
Lopes et al. (2016)
Vyas et al. (2016) (BG)
Vyas et al. (2016) (BG)
Vyas et al. (2016) (FIN)
Vyas et al. (2016) (FIN)
Haisan et al. (2017)
Haisan et al. (2017)
Vyas et al. (2018) (BG)
Vyas et al. (2018) (BG)
Vyas et al. (2018) (BG)
Vyas et al. (2018) (BG)
Vyas et al. (2018) (BG)
Vyas et al. (2018) (FIN)
Vyas et al. (2018) (FIN)
Vyas et al. (2018) (FIN)
Vyas et al. (2018) (FIN)
Vyas et al. (2018) (FIN)

Type $\quad 3$ NOP dose $(\mathrm{mg} / \mathrm{kg})$

Mean Difference $[95 \% \mathrm{Cl}]$

$\begin{array}{lc}2 & 130 \\ 2 & 27 \\ 2 & 135 \\ 1 & 53 \\ 1 & 161 \\ 1 & 345 \\ 2 & 40 \\ 2 & 60 \\ 2 & 80 \\ 1 & 280 \\ 2 & 60 \\ 1 & 100 \\ 1 & 200 \\ 1 & 100 \\ 1 & 200 \\ 2 & 68 \\ 2 & 132 \\ 1 & 50 \\ 1 & 75 \\ 1 & 100 \\ 1 & 150 \\ 1 & 200 \\ 1 & 50 \\ 1 & 75 \\ 1 & 100 \\ 1 & 150 \\ 1 & 200\end{array}$
culated as NOP treatment mean - control treatment mean) in $\mathrm{CH}_{4}$ yield $(\mathrm{g} / \mathrm{kg}$ of DMI) for beef (type $=1)$ and dairy $($ type $=2)$ cattle studies. $\mathrm{BG}=$ backgrounding diet; FIN = finishing diet. The black squares represent the power of the study (i.e., greater sample sizes and smaller confidence intervals are indicated by a larger box). 
the average NOP dose in beef cattle experiments was higher $(144 \mathrm{mg} / \mathrm{kg}$ of DM) than that in dairy cattle (81 $\mathrm{mg} / \mathrm{kg}$ of DM), cattle type as an individual explanatory variable did not affect the decline in $\mathrm{CH}_{4}$ emission with NOP. This indicates that higher NOP doses $(\mathrm{mg} / \mathrm{kg}$ of $\mathrm{DM}$ ) are required for beef cattle than for dairy cattle to achieve a similar reduction in $\mathrm{CH}_{4}$ emission.

The final mixed-effects models for relative $\mathrm{MD}$ in $\mathrm{CH}_{4}$ production and yield (Table 2) included cattle type, NOP dose, and dietary NDF content. The $\tau^{2}$ decreased from the random-effect model to a mixed-effect model with 1 explanatory variable, and further decreased to the final mixed-effect model (Table 2). When adjusted for the effects of NOP dose and dietary NDF content, the $\mathrm{CH}_{4}$-mitigating effect of $\mathrm{NOP}$ was less in beef cattle $(-22.2 \pm 3.33 \%, P=0.003)$ than in dairy cattle $(-39.0 \pm 5.40 \%, P=0.002)$ for $\mathrm{CH}_{4}$ production. For $\mathrm{CH}_{4}$ yield, a similar lower effect was established for beef cattle $(-17.1 \pm 4.23 \%, P=0.016)$ than for dairy cattle $(-38.8 \pm 5.49 \%, P=0.001)$, at a mean NOP dose of $123 \mathrm{mg} / \mathrm{kg}$ of DM and mean NDF content of $331 \mathrm{~g} / \mathrm{kg}$ of DM. The greater efficacy of NOP in decreasing $\mathrm{CH}_{4}$ emissions in dairy cattle compared with beef cattle may be associated with the higher feed intake level in dairy cattle. Higher feed intake levels increase rumen concentrations of fermentation products, including VFA and hydrogen. Although hydrogen appears not to thermodynamically control methanogenesis by archaea, oxidation of NADH in rumen microorganisms, and consequently the type of VFA formed, does appear to be controlled by hydrogen partial pressure (van Lingen et al., 2016), affecting sinks of hydrogen in the rumen. Larger feed intake levels in dairy cattle than in beef cattle may thus be associated with relatively (i.e., per unit of feed fermented) greater alternative hydrogen sinks for ruminal methanogenesis, resulting in relatively lesser concentrations of methyl-coenzyme $\mathrm{M}$ and elevated inhibitory potential of NOP. After adjusting for cattle type and dietary NDF content, the NOP-induced $\mathrm{CH}_{4}$ mitigation was $2.56 \pm 0.550 \%\left(\mathrm{CH}_{4}\right.$ production, $\left.P=0.006\right)$ and $2.48 \pm 0.734 \%\left(\mathrm{CH}_{4}\right.$ yield, $\left.P=0.0216\right)$ per $10 \mathrm{mg} / \mathrm{kg}$ of DM increase in NOP dose from its mean $(123 \mathrm{mg} / \mathrm{kg}$ of DM; Table 2), which is somewhat higher than the effect of NOP dose observed in the individual mixed effect model. In the present analysis, an increase in dietary NDF content decreased the efficacy of NOP in decreasing $\mathrm{CH}_{4}$ emission. A $10 \mathrm{~g} / \mathrm{kg}$ of DM increase in dietary NDF content from its mean $(331 \mathrm{~g} / \mathrm{kg}$ of DM) impaired $(P=0.016)$ the NOP effect on $\mathrm{CH}_{4}$ production decline by $1.64 \pm 0.330 \%$ and impaired $(P=0.029)$ the NOP effect on $\mathrm{CH}_{4}$ yield decline by $1.52 \pm 0.406 \%$ (Table 2 ). Vyas et al. (2018) speculated that the concentration of methyl-coenzyme $\mathrm{M}$ in the rumen was less in cattle fed low-fiber diets than in those fed high-fiber diets. Hence, adding NOP to a low-fiber diet might inhibit MCR with greater efficacy because of this lower concentration of methyl-coenzyme $\mathrm{M}$, explaining the greater inhibitory potential of NOP in low-fiber diets. Mode of delivery of NOP in Reynolds et al. (2014) differed from that in all other experiments. Upon removal of data of Reynolds et al. (2014) from the analyses, the final mixed-effects models did not change and still included cattle type, NOP dose, and dietary NDF content for $\mathrm{CH}_{4}$ production and yield $(P<0.050$; results not shown).

In summary, this meta-analysis indicated that the effectiveness of NOP at mitigating $\mathrm{CH}_{4}$ emissions was positively associated with NOP dose, and negatively associated with dietary fiber content. Moreover, NOP had stronger antimethanogenic effects in dairy cattle than in beef cattle.

\section{ACKNOWLEDGMENTS}

We recognize the thoughtful and focused input of anonymous reviewers in particular on statistical analyses.

\section{REFERENCES}

Appuhamy, J. A. D. R. N., A. B. Strathe, S. Jayasundara, C. WagnerRiddle, J. Dijkstra, J. France, and E. Kebreab. 2013. Anti-methanogenic effects of monensin in dairy and beef cattle: A metaanalysis. J. Dairy Sci. 96:5161-5173.

Benchaar, C., and H. Greathead. 2011. Essential oils and opportunities to mitigate enteric methane emissions from ruminants. Anim. Feed Sci. Technol. 166-167:338-355.

Duin, E. C., T. Wagner, S. Shima, D. Prakash, B. Cronin, D. R. Yáñez-Ruiz, S. Duval, R. Rümbeli, R. T. Stemmler, R. K. Thauer, and M. Kindermann. 2016. Mode of action uncovered for the specific reduction of methane emissions from ruminants by the small molecule 3-nitrooxypropanol. Proc. Natl. Acad. Sci. USA 113:6172-6177.

Fisher, Z., and E. Tipton. 2014. Robumeta: Robust variance metaregression. http://cran.rproject.org/web/packages/robumeta/ index.html.

Haisan, J., Y. Sun, L. Guan, K. A. Beauchemin, A. Iwaasa, S. Duval, M. Kindermann, D. R. Barreda, and M. Oba. 2017. The effects of feeding 3-nitrooxypropanol at two doses on milk production, rumen fermentation, plasma metabolites, nutrient digestibility, and methane emissions in lactating Holstein cows. Anim. Prod. Sci. 57:282-289.

Haisan, J., Y. Sun, L. L. Guan, K. A. Beauchemin, A. Iwaasa, S. Duval, D. R. Barreda, and M. Oba. 2014. The effects of feeding 3-nitrooxypropanol on methane emissions and productivity of Holstein cows in mid lactation. J. Dairy Sci. 97:3110-3119.

Hedges, L. V., E. Tipton, and M. C. Johnson. 2010. Robust variance estimation in metaregression with dependent effect size estimates. Res. Synth. Methods 1:39-65.

Hristov, A. N., J. Oh, J. L. Firkins, J. Dijkstra, E. Kebreab, G. Waghorn, H. P. S. Makkar, A. T. Adesogan, W. Yang, C. Lee, P. J. Gerber, B. Henderson, and J. M. Tricarico. 2013a. Mitigation of methane and nitrous oxide emissions from animal operations: I. A review of enteric methane mitigation options. J. Anim. Sci. 91:5045-5069.

Hristov, A. N., J. Oh, F. Giallongo, T. W. Frederick, M. T. Harper, H. L. Weeks, A. F. Branco, P. J. Moate, M. H. Deighton, S. R. Williams, M. Kindermann, and S. Duval. 2015. An inhibitor per- 
sistently decreased enteric methane emission from dairy cows with no negative effect on milk production. Proc. Natl. Acad. Sci. USA 112:10663-10668.

Hristov, A. N., T. Ott, J. M. Tricarico, C. A. Rotz, G. Waghorn, A. T. Adesogan, J. Dijkstra, F. Montes, J. Oh, E. Kebreab, S. J. Oosting, P. J. Gerber, B. Henderson, H. P. S. Makkar, and J. L. Firkins. 2013b. Mitigation of methane and nitrous oxide emissions from animal operations: III. A review of animal management mitigation options. J. Anim. Sci. 91:5095-5113.

Jayanegara, A., K. Ageng Sarwono, M. Kondo, H. Matsui, M. Ridla, E. B. Laconi, and Nahrowi. 2018. Use of 3-nitrooxypropanol as feed additive for mitigating enteric methane emissions from ruminants: A meta-analysis. Ital. J. Anim. Sci. 17:650-656.

Lopes, J. C., L. F. de Matos, M. T. Harper, F. Giallongo, J. Oh, D. Gruen, S. Ono, M. Kindermann, S. Duval, and A. N. Hristov. 2016. Effect of 3-nitrooxypropanol on methane and hydrogen emissions, methane isotopic signature, and ruminal fermentation in dairy cows. J. Dairy Sci. 99:5335-5344.

Madden, L. V., and P. A. Paul. 2011. Meta-analysis for evidence synthesis in plant pathology: An overview. Phytopathology 101:16-30.

Olijhoek, D. W., A. L. F. Hellwing, M. Brask, M. R. Weisbjerg, O. Højberg, M. K. Larsen, J. Dijkstra, E. J. Erlandsen, and P. Lund. 2016. Effect of dietary nitrate level on enteric methane production, hydrogen emission, rumen fermentation, and nutrient digestibility in dairy cows. J. Dairy Sci. 99:6191-6205.

Rabiee, A. R., I. J. Lean, M. A. Stevenson, and M. T. Socha. 2010. Effects of feeding organic trace minerals on milk production and reproductive performance in lactating dairy cows: A meta-analysis. J. Dairy Sci. 93:4239-4251.

Reynolds, C. K., D. J. Humphries, P. Kirton, M. Kindermann, S. Duval, and W. Steinberg. 2014. Effects of 3-nitrooxypropanol on methane emission, digestion, and energy and nitrogen balance of lactating dairy cows. J. Dairy Sci. 97:3777-3789.

Romero-Perez, A., E. K. Okine, S. M. McGinn, L. L. Guan, M. Oba, S. M. Duval, M. Kindermann, and K. A. Beauchemin. 2014. The potential of 3-nitrooxypropanol to lower enteric methane emissions from beef cattle. J. Anim. Sci. 92:4682-4693.

Romero-Perez, A., E. K. Okine, S. M. McGinn, L. L. Guan, M. Oba, S. M. Duval, M. Kindermann, and K. A. Beauchemin. 2015. Sustained reduction in methane production from long-term addition of 3-nitrooxypropanol to a beef cattle diet. J. Anim. Sci. 93:17801791.

Tanner-Smith, E. E., E. Tipton, and J. R. Polanin. 2016. Handling complex meta-analytic data structures using robust variance estimates: A tutorial in R. J. Dev. Life Course Criminology 2:85-112. van Lingen, H. J., C. M. Plugge, J. G. Fadel, E. Kebreab, A. Bannink, and J. Dijkstra. 2016. Thermodynamic driving force of hydrogen on rumen microbial metabolism: A theoretical investigation. PLoS One 11:e0161362.

Viechtbauer, W. 2010. Conducting meta-analysis in R with the metaphor package. J. Stat. Softw. 36:1-48.

Vyas, D., S. M. McGinn, S. M. Duval, M. Kindermann, and K. A. Beauchemin. 2016. Effects of sustained reduction of enteric methane emissions with dietary supplementation of 3-nitrooxypropanol on growth performance of growing and finishing beef cattle. J. Anim. Sci. 94:2024-2034.

Vyas, D., S. M. McGinn, S. M. Duval, M. K. Kindermann, and K. A. Beauchemin. 2018. Optimal dose of 3-nitrooxypropanol for decreasing enteric methane emissions from beef cattle fed high-forage and high-grain diets. Anim. Prod. Sci. 58:1049-1055. 